\title{
Current Status of Antihypertensive Therapy for Elderly Patients in Japan
}

\author{
Hiromi Muratani*, Koshiro Fukiyama*, **, Tomomasa Kamiyama*, Yorio Kimura*, \\ Keishi Abe ${ }^{* *}$, Masao Ishii**, Jun Fujii ${ }^{* *}$, Iwao Kuwajima**, Toshiaki Shiomi**, \\ Yuhei Kawano**, Hiroshi Mikami**, Setsuro Ibayashi**, and Teruo Omae**
}

\begin{abstract}
To assess how elderly Japanese hypertensive patients are treated by specialists, we conducted a crosssectional survey. A total of 1,163 outpatients aged 50 years or older were studied. Hypertension was diagnosed in 939 of these patients, and 827 were receiving drug therapy. The average blood pressure during therapy was $143 \pm 16 / 81 \pm 10 \mathrm{mmHg}$. In patients aged 70 years or older, systolic blood pressure during antihypertensive therapy was significantly higher $(p<0.01)$ and diastolic blood pressure was significantly lower $(p<0.01)$ than the corresponding values in those aged 50 to 59 years or 60 to 69 years. The calculated mean blood pressures were similar in the different age groups. The rate of monotherapy in the patients aged 70 years or older was $58.8 \%$, which was significantly higher $(p<0.01)$ than the rates of monotherapy in the other age groups. Calcium channel blockers were prescribed in about $80 \%$ of patients, irrespective of age or comorbidity. Of the patients receiving calcium channel blockers, 43.5\% were treated with monotherapy. This rate significantly $(p<0.01)$ increased with advancing age. Diastolic blood pressures were significantly lower $(p<0.05)$ in patients with stroke and in those with ischemic heart disease, diabetes mellitus, or dyslipidemia, as compared with patients with no comorbidity. Among patients aged 70 years or older, the difference in systolic blood pressure between those with ischemic heart disease and those with no comorbidity was not significant. Blood pressure in elderly hypertensive patients was reduced to a level similar to that in younger patients. The target blood pressure was influenced by the presence of comorbidity. Furthermore, specialists showed a high preference for the use of calcium channel blockers in the management of hypertension. (Hypertens Res 1996; 19: 281-290)
\end{abstract}

Key words: elderly patient, antihypertensive therapy, calcium channel blocker, target-organ damage, risk factor

In Western countries, antihypertensive therapy has been reported to reduce the incidence of cardiovascular and cerebrovascular events among elderly patients with hypertension (1-4). Therefore, most physicians agree that both elderly and younger patients with hypertension should receive antihypertensive therapy. However, there is a lack of consensus about the level of blood pressure that should be treated and how far the blood pressure should be reduced in elderly patients. Moreover, it is uncertain whether currently available antihypertensive therapy improves activities of daily living (ADL) or the quality of life (QOL) in elderly patients.

We conducted a cross-sectional survey in 1995 to study effects of blood pressure on ADL in elderly patients. This survey was performed in a collabora- tion with The Research Group on Evaluation of the Effects of Drug Treatment on Hypertension and Other Disease Conditions in the Elderly. The data obtained from this survey were analyzed to assess how elderly hypertensive patients are treated in Japan. Here we address issues such as whether the target blood pressure or the type of antihypertensive therapy is influenced by the patients' age and associated cardiovascular complications or risk factors. The results of ADL analysis will be published elsewhere.

\section{Subjects and Methods}

Patient Enrollment

This cross-sectional survey was performed at 11 hospitals, where the members of the research group or

From the * Third Department of Internal Medicine, University of the Ryukyus School of Medicine, Okinawa, Japan, and ** The Research Group on Evaluation of the Effects of Drug Treatment on Hypertension and Other Disease Conditions in the Elderly, Japan.

This study was supported by a research grant from the Funds for Comprehensive Research on Aging and Health (94A2101).

Address for Reprints: Hiromi Muratani, M.D., Third Department of Internal Medicine, University of the Ryukyus School of Medicine, 207 Uehara, Nishihara-cho, Okinawa 903-01, Japan.

Received July 4, 1996; accepted in revised form September 6, 1996. 
their collaborators had outpatient clinics. Outpatients aged 50 years or older were asked to fill out a questionnaire to evaluate their ADL. Assistance was provided by their attending physicians if necessary. At the same time, their attending physicians filled out a case report form for each patient. Items included gender, personal history, clinical diagnosis, details of therapy, physical findings such as height and body weight, blood pressure, pulse rate, and laboratory data. At each visit, sitting blood pressure was measured twice by the attending physician with a standard mercury sphygmomanometer. The average of the two readings was recorded for that day. The average of the blood pressure readings taken on two consecutive visits, including the day on which ADL was evaluated, was recorded in the case report form. Age was calculated by subtracting the birth date of the subject from the date of the survey. Patients with malignant tumors, or other lifethreatening conditions were not eligible. Patients with dementia, diabetes mellitus with advanced complications such as proliferative retinopathy, renal failure, or disabling autonomic neuropathy were also excluded.

The diagnosis of hypertension was based on the Fifth Report of the Joint National Committee on Detection, Evaluation, and Treatment of High Blood Pressure (5). In principle, patients receiving antihypertensive drug(s) were given a diagnosis of hypertension. However, 25 patients who were receiving antihypertensive drugs were reported by their attending physicians to be normotensive. Because "antihypertensive" drugs were prescribed to these patients for indications other than hypertension, such as ischemic heart disease, they were considered normotensive. Diabetes mellitus was diagnosed when the fasting plasma glucose concentration was $140 \mathrm{mg} / \mathrm{dl}$ or more, when the diagnosis was confirmed by a 75 -g oral glucose tolerance test (6), or when the patient was receiving an oral hypoglycemic agent or insulin. Dyslipidemia was diagnosed when the serum total cholesterol concentration was $220 \mathrm{mg} / \mathrm{dl}$ or more, the serum triglyceride concentration $150 \mathrm{mg} / \mathrm{dl}$ or more, or both. Dyslipidemia was also diagnosed if the patient was taking an antihyperlipidemic agent. Obesity and renal insufficiency were diagnosed when the body mass index was $25 \mathrm{~kg} / \mathrm{m}^{2}$ or more and when the serum creatinine concentration was $2 \mathrm{mg} / \mathrm{dl}$ or more, respectively.

A total of 1,163 patients filled out the questionnaire, and their attending physicians provided the profile data for each subject. Five patients whose case report forms included no information as to whether they were normotensive or hypertensive were excluded from data analysis. Thus, data from 1,158 patients were analyzed. Because the research group members and their collaborators were specialists in antihypertensive therapy, about $80 \%$ of the subjects had hypertension, that is, 219 of the eligible 1,158 patients were normotensive, and 939 patients were hypertensive. Thirty-six patients with hypertension were not receiving drug therapy. In addition, information on whether or not anti- hypertensive drugs were being prescribed was not available for 76 hypertensive patients.

\section{Analysis of Profile Data}

The subjects were divided into three age groups: 50 to 59 years old, 60 to 69 years old, and 70 years old or older. Blood pressure during antihypertensive therapy and types of antihypertensive drugs prescribed were compared among the three age groups. In addition, whether the presence of diabetes mellitus, dyslipidemia, obesity, or renal insufficiency had any effect on the blood pressure or on the type of antihypertensive therapy prescribed was analyzed. We also investigated whether a history of stroke or cardiovascular events, such as myocardial infarction or angina pectoris, affected the type of antihypertensive therapy prescribed. For this analysis, patients with a history of stroke were subgrouped together. Likewise, patients with a history of myocardial infarction or angina pectoris were combined to yield a subgroup of patients with ischemic heart disease.

Data analysis was performed with the use of Statistical Analysis System (SAS) (7). Comparisons among groups were performed by analysis of variance followed by multiple comparison by Duncan's multiple range test; for comparisons of frequency, the Mantel-Haenszel chi-square test was used. $p$-values less than 0.05 were considered to be indicating statistical significance.

\section{Results}

\section{Clinical Characteristics}

The clinical characteristics of eligible subjects are summarized in Tables 1-A and 1-B. In hypertensive patients, the average systolic blood pressure during antihypertensive therapy was $143 \pm 16 \mathrm{mmHg}$, while the average diastolic blood pressure was $81 \pm 10$ $\mathrm{mmHg}$. Blood pressure level was similar in the three hypertensive subgroups, i.e., those not receiving drug therapy, those receiving drug therapy, and those in whom this information was not available. Both systolic and diastolic blood pressures were significantly $(p<0.01)$ higher in the hypertensive patients than in the normotensive subjects. Pulse rate did not differ between the normotensive and hypertensive patients. Administration of antihypertensive drugs did not alter the pulse rate. In addition, body mass index was significantly higher $(p<0.05)$ in hypertensive patients who were receiving drug therapy than in normotensive patients (Table 1-A). Normotensive patients prescribed "antihypertensive" drugs had a significantly higher $(p<0.05)$ mean serum creatinine concentration than the other groups, with the exception of hypertensive patients not receiving drug therapy. Blood urea nitrogen, fasting blood sugar, serum total cholesterol, and HDL-cholesterol levels were not significantly different among the groups (Table 1-B). When the subjects were divided into the three age groups, there were also no significant differences in these variables. 
Table 1-A. Clinical Characteristics of Subjects: Gender, Age, Blood Pressure, Heart Rate, and Body Mass Index

\begin{tabular}{|c|c|c|c|c|c|}
\hline & Men/Women & $\begin{array}{c}\text { Age } \\
\text { (years old) }\end{array}$ & $\begin{array}{l}\text { Blood pressure } \\
(\mathrm{mmHg})\end{array}$ & $\begin{array}{l}\text { Pulse rate } \\
\text { (beats/min) }\end{array}$ & $\begin{array}{l}\text { Body mass index } \\
\left(\mathrm{kg} / \mathrm{m}^{2}\right)\end{array}$ \\
\hline $\begin{array}{c}\text { Normotension } \\
n=194\end{array}$ & $99 / 95$ & $\begin{array}{l}67.4 \pm 9.0 \\
(194)\end{array}$ & $\begin{array}{c}131 \pm 13 / 75 \pm 8 \\
(193)\end{array}$ & $\begin{array}{l}71 \pm 8 \\
(187)\end{array}$ & $\begin{array}{l}22.5 \pm 3.1 \\
\quad(177)\end{array}$ \\
\hline $\begin{array}{l}\text { Normotension with "antihypertensive" drugs (1) } \\
\quad n=25\end{array}$ & $18 / 7$ & $\begin{array}{c}64.9 \pm 10.5 \\
(25)\end{array}$ & $\begin{array}{c}131 \pm 15 / 73 \pm 12 \\
(24)\end{array}$ & $\begin{array}{l}72 \pm 8 \\
(24)\end{array}$ & $\begin{array}{l}22.3 \pm 3.5 \\
\quad(21)\end{array}$ \\
\hline $\begin{array}{l}\text { Hypertension without drug treatment } \\
\qquad n=36\end{array}$ & $18 / 18$ & $\begin{array}{c}66.5 \pm 11.4 \\
(36)\end{array}$ & $\begin{array}{c}148 \pm 15 * * / 82 \pm 8 * * \\
(36)\end{array}$ & $\begin{array}{l}73 \pm 8 \\
(35)\end{array}$ & $\begin{array}{l}23.8 \pm 2.7 \\
\quad(34)\end{array}$ \\
\hline $\begin{array}{l}\text { Hypertension with drug treatment } \\
\quad n=827\end{array}$ & $416 / 411$ & $\begin{array}{l}66.9 \pm 9.2 \\
(827)\end{array}$ & $\begin{array}{c}143 \pm 16^{* *} / 81 \pm 10^{* *} \\
(820)\end{array}$ & $\begin{array}{l}70 \pm 9 \\
(804)\end{array}$ & $\begin{array}{l}24.0 \pm 3.2 * \\
\quad(779)\end{array}$ \\
\hline $\begin{array}{l}\text { Hypertension with unknown drug status (2) } \\
\quad n=76\end{array}$ & $31 / 45$ & $\begin{array}{c}66.0 \pm 8.6 \\
(76)\end{array}$ & $\begin{array}{c}145 \pm 17 * * / 83 \pm 10^{* *} \\
(76)\end{array}$ & $\begin{array}{c}72 \pm 8 \\
(76)\end{array}$ & $\begin{array}{c}23.0 \pm 3.6 \\
(76)\end{array}$ \\
\hline $\begin{array}{l}\text { Total } \\
\qquad n=1158\end{array}$ & $582 / 576$ & $\begin{array}{c}66.8 \pm 9.2 \\
(1158) \\
\end{array}$ & $\begin{array}{c}141 \pm 16 / 80 \pm 10 \\
(1149)\end{array}$ & $\begin{array}{l}71 \pm 9 \\
(1126)\end{array}$ & $\begin{array}{c}23.7 \pm 3.3 \\
(1086)\end{array}$ \\
\hline
\end{tabular}

Data are mean $\pm \mathrm{SD} .{ }^{*} p<0.05 v s$. normotension, ${ }^{* *} p<0.01 v s$. normotension, normotension with "antihypertensive" drugs.

Table 1-B. Clinical Characteristics of Subjects: Blood Chemistry

\begin{tabular}{|c|c|c|c|c|c|c|c|}
\hline & $\begin{array}{c}\mathrm{S}-\mathrm{Na} \\
(\mathrm{mEq} / \mathrm{l})\end{array}$ & $\begin{array}{c}\mathrm{S}-\mathrm{K} \\
(\mathrm{mEq} / \mathrm{l})\end{array}$ & $\begin{array}{c}\text { BUN } \\
(\mathrm{mg} / \mathrm{dl})\end{array}$ & $\begin{array}{l}\text { Creatinine } \\
(\mathrm{mg} / \mathrm{dl})\end{array}$ & $\begin{array}{c}\text { FBS } \\
(\mathrm{mg} / \mathrm{dl})\end{array}$ & $\begin{array}{c}\mathrm{TC} \\
(\mathrm{mg} / \mathrm{dl})\end{array}$ & $\begin{array}{l}\text { HDL-C } \\
(\mathrm{mg} / \mathrm{dl}) \\
\end{array}$ \\
\hline $\begin{array}{c}\overline{\text { Normotension }} \\
n=194\end{array}$ & $\begin{array}{c}142 \pm 3 \\
(190)\end{array}$ & $\begin{array}{l}4.2 \pm 0.4 \\
(189)\end{array}$ & $\begin{array}{c}16.7 \pm 5.2 \\
(188)\end{array}$ & $\begin{array}{l}0.9 \pm 0.4 \\
(190)\end{array}$ & $\begin{array}{c}103 \pm 28 \\
(160)\end{array}$ & $\begin{array}{c}204 \pm 36 \\
(189)\end{array}$ & $\begin{array}{c}52 \pm 18 \\
(141)\end{array}$ \\
\hline $\begin{array}{l}\text { Normotension with "antihypertensive" drugs (1) } \\
\quad n=25\end{array}$ & $\begin{array}{l}141 \pm 2 \\
(25)\end{array}$ & $\begin{array}{l}4.3 \pm 0.3 \\
(25)\end{array}$ & $\begin{array}{c}19.7 \pm 14.0 \\
(25)\end{array}$ & $\begin{array}{c}1.2 \pm 1.2 * \\
(25)\end{array}$ & $\begin{array}{l}101 \pm 20 \\
(18)\end{array}$ & $\begin{array}{l}191 \pm 31 \\
(23)\end{array}$ & $\begin{array}{c}47 \pm 18 \\
(20)\end{array}$ \\
\hline $\begin{array}{l}\text { Hypertension without drug treatment } \\
\quad n=36\end{array}$ & $\begin{array}{c}142 \pm 3 \\
(34)\end{array}$ & $\begin{array}{l}4.2 \pm 0.4 \\
(34)\end{array}$ & $\begin{array}{c}17.2 \pm 4.4 \\
(34)\end{array}$ & $\begin{array}{l}1.0 \pm 0.6 \\
(35)\end{array}$ & $\begin{array}{l}102 \pm 21 \\
(27)\end{array}$ & $\begin{array}{c}205 \pm 35 \\
(35)\end{array}$ & $\begin{array}{c}49 \pm 16 \\
(29)\end{array}$ \\
\hline $\begin{array}{l}\text { Hypertension with drug treatment } \\
\qquad n=827\end{array}$ & $\begin{array}{l}142 \pm 3 \\
(807)\end{array}$ & $\begin{array}{l}4.2 \pm 0.4 \\
\quad(807)\end{array}$ & $\begin{array}{c}17.8 \pm 7.5 \\
(797)\end{array}$ & $\begin{array}{l}0.9 \pm 0.5 \\
(815)\end{array}$ & $\begin{array}{c}104 \pm 27 \\
(719)\end{array}$ & $\begin{array}{l}205 \pm 32 \\
(814)\end{array}$ & $\begin{array}{c}53 \pm 17 \\
(731)\end{array}$ \\
\hline $\begin{array}{l}\text { Hypertension with unknown drug status (2) } \\
\quad n=76\end{array}$ & $\begin{array}{l}142 \pm 2 \\
(76)\end{array}$ & $\begin{array}{l}4.2 \pm 0.4 \\
(76)\end{array}$ & $\begin{array}{c}16.3 \pm 6.6 \\
(76)\end{array}$ & $\begin{array}{l}0.8 \pm 0.3 \\
(76)\end{array}$ & $\begin{array}{c}106 \pm 26 \\
(65)\end{array}$ & $\begin{array}{c}205 \pm 33 \\
(75)\end{array}$ & $\begin{array}{c}57 \pm 20 \\
(70)\end{array}$ \\
\hline $\begin{array}{l}\text { Total } \\
\qquad n=1158\end{array}$ & $\begin{array}{c}142 \pm 3 \\
(1132)\end{array}$ & $\begin{array}{c}4.2 \pm 0.4 \\
(1131)\end{array}$ & $\begin{array}{c}17.6 \pm 7.3 \\
(1120)\end{array}$ & $\begin{array}{c}0.9 \pm 0.5 \\
(1141)\end{array}$ & $\begin{array}{c}104 \pm 27 \\
(989)\end{array}$ & $\begin{array}{c}205 \pm 33 \\
(1136)\end{array}$ & $\begin{array}{c}53 \pm 17 \\
(991)\end{array}$ \\
\hline
\end{tabular}

Data are mean $\pm \mathrm{SD} .{ }^{*}: p<0.05 v s$. normotension, hypertension with drug treatment, hypertension with unknown drug status.

(1) In 25 normotensive subjects, "antihypertensive" drugs were prescribed for diseases other than hypertension, mainly for ischemic heart disease. (2) In 76 hypertensive subjects, it was not specified if antihypertensive drugs were prescribed. Values in the parentheses indicate the number of subjects in whom the variable was measured.

Number of Antihypertensive Drugs Administered and Blood Pressure Level during Antihypertensive Therapy

Average blood pressure and pulse rate in each age group are summarized in Table 2 according to the number of antihypertensive drugs administered. More than $80 \%$ of the patients received one or two drugs. As compared with patients aged 50 to 59 years and those aged 60 to 69 years, the rate of monotherapy was significantly higher $(p<0.01)$ in patients aged 70 years or older. Both as an entire group or in the subgroup of patients receiving monotherapy, systolic blood pressures were significantly higher $(p<0.01)$ and diastolic blood pressures were significantly lower $(p<0.01)$ among pa- tients aged 70 years or older than in the other two age groups. The calculated mean blood pressure was similar in the three age groups. However, there were no significant differences in systolic blood pressure among the age groups in patients receiving two drugs or more. Pulse rate did not differ among the age groups irrespective of the number of drugs administered.

Table 2 also shows that in each age group, the number of antihypertensive drugs administered did not influence systolic blood pressure during antihypertensive therapy. In other words, systolic blood pressure levels were similar among the groups receiving monotherapy, two drugs, and three drugs or more. On the other hand, in the age group of 70 
Table 2. Blood Pressure Level During Antihypertensive Therapy

\begin{tabular}{|c|c|c|c|c|}
\hline & 50-59 y.o. & 60-69 y.o. & 70 y.o.- & Total \\
\hline \multicolumn{5}{|l|}{ Monotherapy } \\
\hline Blood pressure & $142 \pm 15 / 85 \pm 9$ & $141 \pm 14 / 82 \pm 9$ & $146 \pm 15^{* *} / 79 \pm 9 * *$ & $143 \pm 15 / 81 \pm 9$ \\
\hline (beats/min) & $72 \pm 8$ & $71 \pm 10$ & $73 \pm 10$ & $72 \pm 10$ \\
\hline$n$ & $62(34.6)$ & $170(49.6)$ & $177(58.8)$ & $409(49.9)$ \\
\hline \multicolumn{5}{|l|}{ Two drugs } \\
\hline Blood pressure $\quad(\mathrm{mmHg})$ & $140 \pm 16 / 86 \pm 10$ & $141 \pm 15 / 80 \pm 10^{*}$ & $144 \pm 18 / 77 \pm 9 * *$ & $142 \pm 16 / 81 \pm 10$ \\
\hline (beats/min) & $68 \pm 8$ & $69 \pm 9$ & $70 \pm 8$ & $69 \pm 9$ \\
\hline$n$ & $69(40.7)$ & $127(37.0)$ & $77(25.6)$ & $273(33.3)$ \\
\hline \multicolumn{5}{|l|}{ Three drugs or more } \\
\hline Blood pressure $\quad(\mathrm{mmHg})$ & $138 \pm 19 / 84 \pm 10$ & $143 \pm 20 / 83 \pm 10$ & $147 \pm 21 / 75 \pm 10^{\dagger}$ & $143 \pm 20 / 81 \pm 11$ \\
\hline (beats/min) & $69 \pm 8$ & $66 \pm 9$ & $68 \pm 11$ & $68 \pm 10$ \\
\hline$n$ & $45(24.7)$ & $46(13.4)$ & $47(15.6)$ & $138(16.8)$ \\
\hline \multicolumn{5}{|l|}{ Total } \\
\hline Blood pressure $\quad(\mathrm{mmHg})$ & $140 \pm 16 / 85 \pm 10$ & $141 \pm 15 / 81 \pm 9$ & $146 \pm 17 * * / 78 \pm 10 * *$ & $143 \pm 16 / 81 \pm 10$ \\
\hline Pulse rate (beats $/ \mathrm{min}$ ) & $69 \pm 8$ & $70 \pm 10$ & $72 \pm 10$ & $70 \pm 9$ \\
\hline$n$ & $176(100)$ & $343(100)$ & $301(100)$ & $820(100)$ \\
\hline
\end{tabular}

Data are mean \pm SD. ${ }^{* *} p<0.05$ vs. 50-59 y.o., 60-69 y.o. ${ }^{*} p<0.05$ vs. $50-59$ y.o. ${ }^{\dagger} p<0.05$ vs. monotherapy.

Values in the parentheses represent the percentage to the number of subjects in each age group. The numbers of subjects differ from those appearing in Fig. 1, because blood pressure and pulse rate were not available for 7 patients.
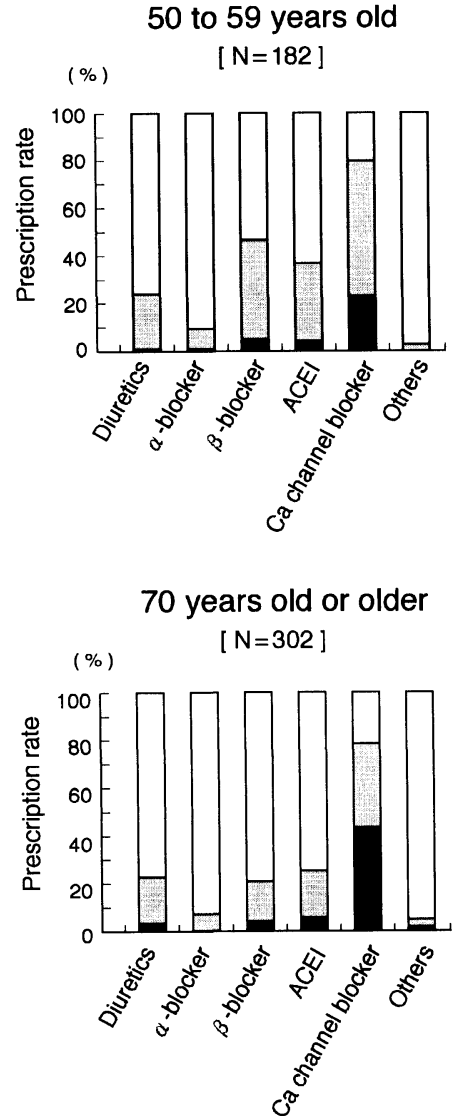

60 to 69 years old

$[\mathrm{N}=343$ ]

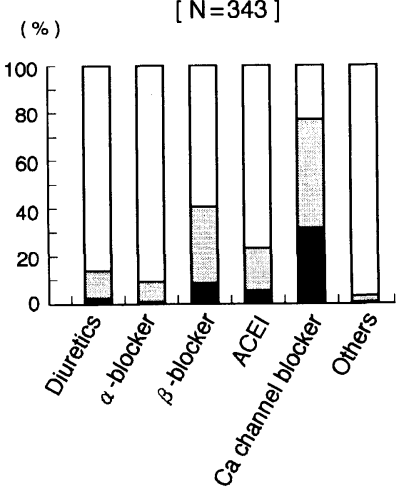

Total subjects

[ $N=827$ ]

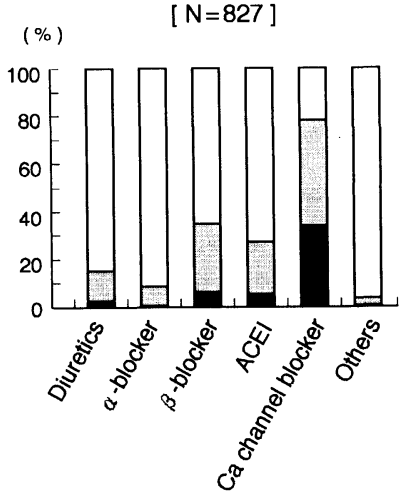

Not Used

Combination

Therapy

Monotherapy

Fig. 1. Prescription rate of each class of antihypertensive drug according to age group. ACEI: angiotensin converting enzyme inhibitors. 

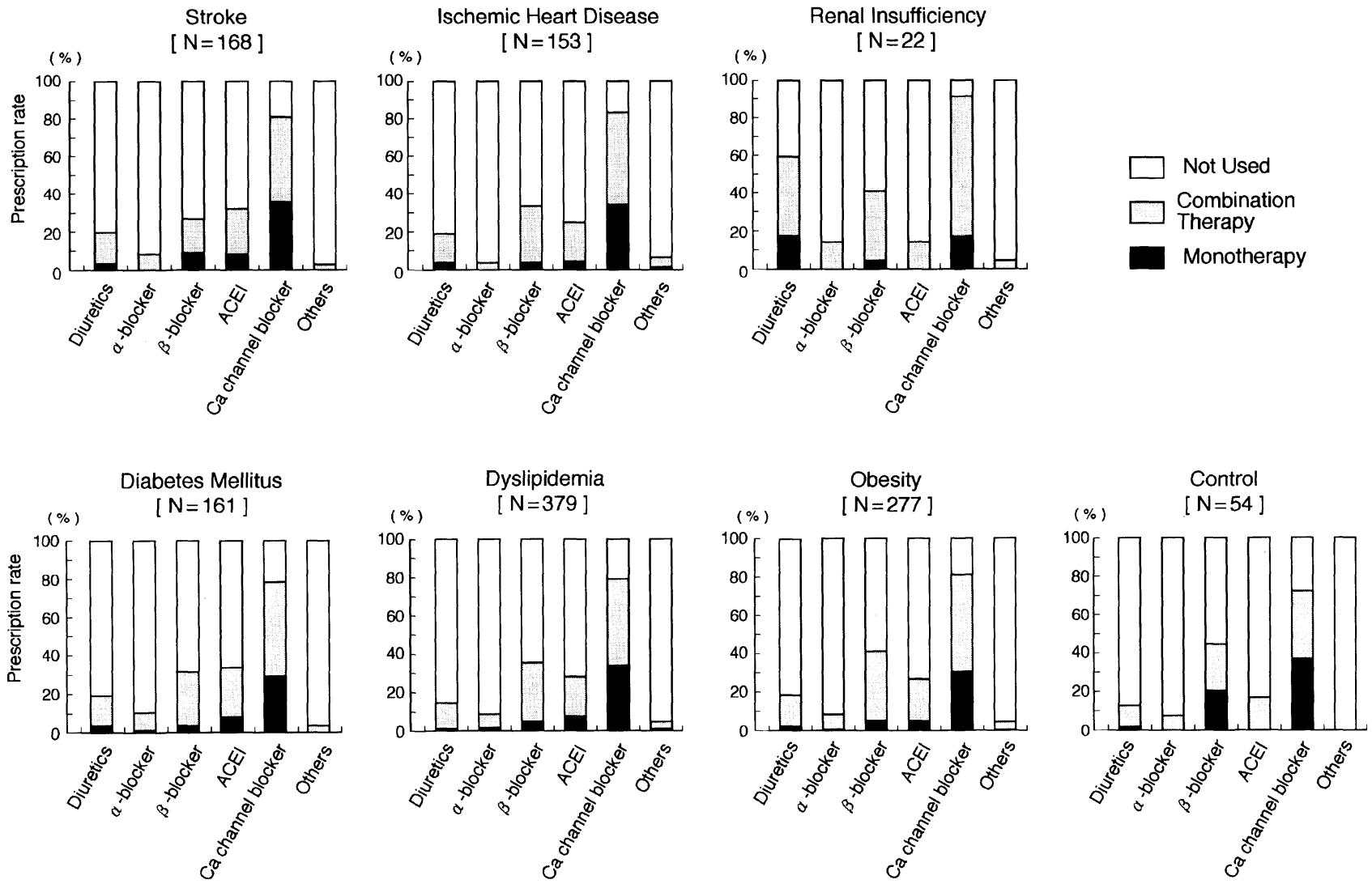

Fig. 2. Prescription rate of each class of antihypertensive drug according to concurrent disease. Control group consists of patients with no complications or risk factors. The age of each group was as follows: $69.2 \pm 9.0$ years in patients with stroke, $70.5 \pm 9.8$ years in those with ischemic heart disease, 68.0 \pm 10.4 years in those with renal insufficiency, $67.7 \pm 8.8$ years in those with diabetes mellitus, $66.2 \pm 8.8$ years in those with dyslipidemia, $64.5 \pm 8.6$ years in those with obesity, and $65.7 \pm 8.4$ years in the control group. ACEI: angiotensin converting enzyme inhibitors.

years or older, diastolic blood pressure was slightly but significantly lower $(p<0.05)$ in patients given three or more drugs as compared with those given monotherapy.

Prescription Rate of Each Class of Antihypertensive Drug

As a whole, the most frequently prescribed class of antihypertensive drug was, in decreasing order, as follows: calcium channel blockers, $\beta$-blockers, angiotensin converting enzyme inhibitors, diuretics, $\alpha$-blockers, and other classes of drugs (Fig. 1, right lower panel). Calcium channel blockers were administered to about $80 \%$ of patients. This frequency was similar among the three age groups. $\beta$-blockers were administered to more than one third of the patients. However, the prescription rate of $\beta$-blockers was higher in patients aged 50 to 59 years than in older patients and then significantly $(p<0.01)$ decreased with advancing age. Likewise, the prescription rate of angiotensin converting enzyme inhibitors was significantly higher $(p<0.05)$ in patients aged 50 to 59 years.

Figure 1 also shows that a calcium channel blocker was most frequently prescribed drug for monotherapy. More than two-fifths of the patients who received calcium channel blockers were treated with this class of drug alone. The prescription rate of calcium channel blockers as monotherapy significantly $(p<0.01)$ increased with advancing age. When other classes of antihypertensive drugs were administered, less than one-fifth of the patients received monotherapy. As for diuretics, $\beta$-blockers, and angiotensin converting enzyme inhibitors, the prescription rate of these drugs as monotherapy tended to be higher $(p=0.1)$ in patients aged 60 to 69 years and 70 years or older than in those aged 50 to 59 years.

\section{Influence of Cardiovascular Complications and Risk} Factors on the Strategy for Antihypertensive Therapy We analyzed whether associated cardiovascular complications and risk factors affected the prescription rate of each class of antihypertensive drug and the blood pressure level during antihypertensive therapy. For comparison, a subgroup of hypertensive patients with no complications served as control. This group consisted of 54 non-smoking patients with no evidence of stroke, ischemic heart disease, renal impairment, arteriosclerosis obliterans, atherosclerosis of the carotid artery, diabetes mellitus, dyslipidemia, and obesity. 

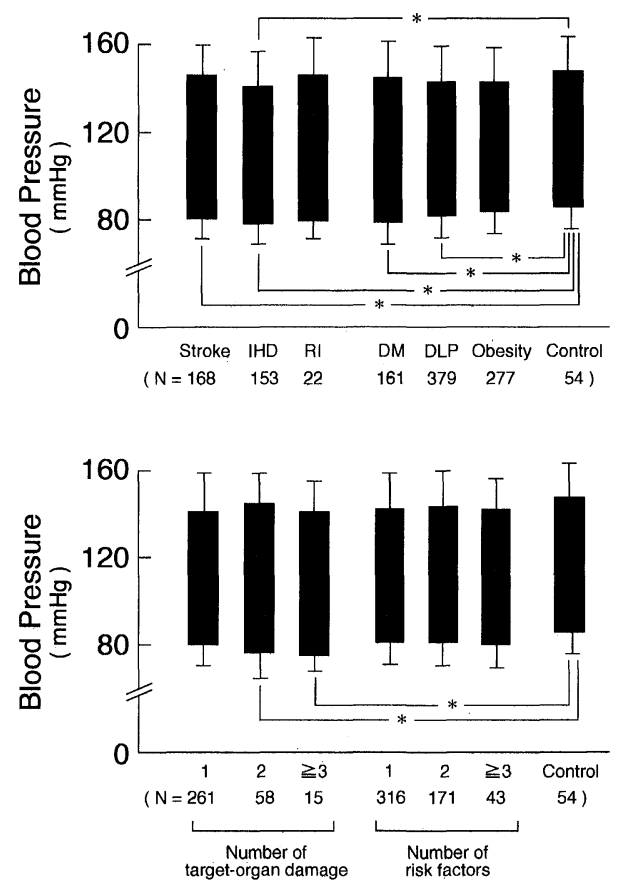

Fig. 3. Blood pressure and pulse rate during antihypertensive therapy according to concurrent disease, target-organ damage, and risk factors. Control group consists of patients with no complications or risk factors. ${ }^{*} \mathrm{p}<$ 0.05 vs. control group. DLP: dyslipidemia, DM: diabetes mellitus, IHD: ischemic heart disease, RI: renal insufficiency.

Calcium channel blockers were prescribed to about $80 \%$ of the patients and were far more frequently used as monotherapy than other classes of drugs, irrespective of the patients' concurrent disease status (Fig. 2). Thus, the presence of complications did not affect the use of calcium channel blockers. In contrast, the use of diuretics was apparently higher in patients with renal insufficiency. As compared with the control group, the prescription rate of angiotensin converting enzyme inhibitors was significantly $(p<0.05)$ higher in patients with stroke and those with diabetes mellitus. The prescription rate of $\beta$-blockers in patients with stroke was significantly $(p<0.05)$ lower than in the control group. Furthermore, there was a trend toward a lower prescription rate of $\beta$-blockers in patients with diabetes mellitus, dyslipidemia, or ischemic heart disease. Conversely, the prescription rate of angiotensin converting enzyme inhibitors was slightly, although not significantly, higher in patients with dyslipidemia, obesity, or ischemic heart disease (Fig. 2). Even when two or more cardiovascular complications or risk factors were present in a single patient, there was no change in the prescription rate of each class of antihypertensive therapy.

We also studied whether the blood pressure level during antihypertensive therapy was affected by the presence of comorbidity. Overall, diastolic blood pressures were significantly lower $(p<0.05)$ in stroke patients or those with ischemic heart disease, diabetes mellitus, or dyslipidemia than in the control group (Fig. 3, upper panel). Systolic blood pressure was also significantly lower $(p<0.05)$ in patients with ischemic heart disease than in the control group (Fig. 3, upper panel). When data were analyzed according to age group, diastolic blood pressures were significantly lower in patients with diabetes mellitus in each of the age groups and in patients with ischemic heart disease who were 60 to 69 years old or 70 years old or older than in the respective control subjects (Table 3 ). Systolic blood pressure in patients with dyslipidemia who were 60 to 69 years old was significantly lower than that in the control patients of the same age group. However, among patients aged 70 years or older, the difference in systolic blood pressure between those with ischemic heart disease and the control group was not significant (Table 3).

When two or more complications were present in a single patient, diastolic but not systolic blood pressure was significantly $(p<0.05)$ lower than in the control group (Fig. 3, lower panel). However, when the data were analyzed according to age group, diastolic blood pressure during antihypertensive therapy was not influenced by the presence of multiple cardiovascular complications (Table 4). The presence of two or more risk factors in a single patient did not influence the blood pressure level during antihypertensive therapy (Fig. 3, lower panel, and Table 4).

\section{Discussion}

This survey was performed by specialists in antihypertensive therapy. The results therefore reflect how elderly patients with hypertension are treated by specialists in Japan. In addition, strategies of antihypertensive therapy in elderly patients were compared with those in younger patients.

\section{Blood Pressure Level and Number of Drugs Admin- istered}

Average blood pressure during antihypertensive therapy was $143 \pm 16 / 81 \pm 10 \mathrm{mmHg}$. Systolic blood pressure was significantly higher and diastolic blood pressure was significantly lower in patients aged 70 years or older than in the younger age groups (Table 3). Calculated mean blood pressures were similar in the three age groups. Although this study was not designed to analyze blood pressure control on an individual case basis, we assume that both the systolic and diastolic blood pressures approximated the goals of antihypertensive therapy. The fact that patients aged 70 years or older more frequently received monotherapy than younger patients suggests that hypertension in elderly patients is relatively easy to control.

The average blood pressure during antihypertensive therapy in patients aged 70 years or older, 146 $\pm 17 / 78 \pm 10 \mathrm{mmHg}$, is lower than the target blood pressure level according to the results of a questionnaire survey of Japanese specialists in hypertension (8), which recommended a blood pressure less than $150 / 90 \mathrm{mmHg}$ for patients aged 60 to 69 years and 
Table 3. Blood Pressure and Pulse Rate during Antihypertensive Therapy According to Concurrent Disease and Age Group

\begin{tabular}{|c|c|c|c|c|}
\hline & & 50-59 у.о. & 60-69 y.o. & 70 y.o.- \\
\hline \multirow{3}{*}{ Control Group } & Blood pressure $(\mathrm{mmHg})$ & $149 \pm 17 / 90 \pm 8$ & $146 \pm 14 / 83 \pm 6^{*}$ & $143 \pm 19 / 82 \pm 10^{*}$ \\
\hline & Pulse rate (beats $/ \mathrm{min})$ & $72 \pm 9$ & $68 \pm 9$ & $72 \pm 7$ \\
\hline & $n$ & 12 & 28 & 14 \\
\hline \multicolumn{5}{|c|}{ Patients with Cardiovascular Complications } \\
\hline \multirow{3}{*}{ Stroke } & Blood pressure $(\mathrm{mmHg})$ & $138 \pm 20 / 84 \pm 10$ & $144 \pm 15 / 80 \pm 9 *$ & $146 \pm 14 * / 78 \pm 8^{*}$ \\
\hline & Pulse rate (beats $/ \mathrm{min})$ & $70 \pm 7$ & $71 \pm 9$ & $72 \pm 8$ \\
\hline & $n$ & 26 & 56 & 86 \\
\hline \multirow{3}{*}{ Ischemic heart disease } & Blood pressure $(\mathrm{mmHg})$ & $132 \pm 14^{\dagger} / 83 \pm 10$ & $137 \pm 16^{\dagger} / 77 \pm 13^{* \dagger}$ & $142 \pm 16^{*} / 76 \pm 10^{* \dagger}$ \\
\hline & Pulse rate (beats $/ \mathrm{min})$ & $63 \pm 7^{\dagger}$ & $71 \pm 10$ & $74 \pm 10$ \\
\hline & $n$ & 19 & 58 & 76 \\
\hline \multirow{3}{*}{ Renal insufficiency } & Blood pressure $(\mathrm{mmHg})$ & $140 \pm 18 / 78 \pm 10$ & $156 \pm 17 / 79 \pm 9$ & $142 \pm 15 / 79 \pm 7$ \\
\hline & Pulse rate (beats/min) & $66 \pm 2$ & $71 \pm 9$ & $69 \pm 7$ \\
\hline & $n$ & 6 & 5 & 11 \\
\hline \multicolumn{5}{|c|}{ Patients with Risk Factors } \\
\hline \multirow{3}{*}{ Diabetes mellitus } & Blood pressure $(\mathrm{mmHg})$ & $140 \pm 17 / 81 \pm 11^{\dagger}$ & $141 \pm 13 / 80 \pm 9^{\dagger}$ & $148 \pm 18 * / 76 \pm 10^{*+}$ \\
\hline & Pulse rate (beats/min) & $73 \pm 10$ & $69 \pm 9$ & $72 \pm 10$ \\
\hline & $n$ & 28 & 67 & 66 \\
\hline \multirow{3}{*}{ Hyperlipidemia } & Blood pressure $(\mathrm{mmHg})$ & $141 \pm 15 / 86 \pm 8$ & $140 \pm 15^{\dagger} / 82 \pm 9^{*}$ & $146 \pm 18^{* *} / 78 \pm 10^{* *}$ \\
\hline & Pulse rate (beats/min) & $68 \pm 8$ & $69 \pm 9$ & $70 \pm 8$ \\
\hline & $n$ & 85 & 163 & 131 \\
\hline \multirow[t]{2}{*}{ Obesity } & Blood pressure $(\mathrm{mmHg})$ & $140 \pm 15 / 86 \pm 9$ & $142 \pm 14 / 83 \pm 9 *$ & $147 \pm 17^{* *} / 78 \pm 9^{* *}$ \\
\hline & $\begin{array}{l}\text { Pulse rate } \\
n\end{array}$ & $\begin{array}{c}70 \pm 8 \\
79\end{array}$ & $\begin{array}{c}68 \pm 8 \\
126\end{array}$ & $\begin{array}{c}71 \pm 9 \\
72\end{array}$ \\
\hline
\end{tabular}

Data are mean \pm SD. ${ }^{* *} p<0.05$ vs. 50-59 y.o., $60-69$ y.o. ${ }^{*} p<0.05$ vs. $50-59$ y.o. ${ }^{\dagger} p<0.05$ vs. control Group. Control group consists of patients with no complications or risk factors.

less than $160 / 90 \mathrm{mmHg}$ for those aged 70 to 79 years. Although the results of this questionnaire survey $(8)$ indicated that many specialists feel that elderly patients are more susceptible to potential adverse effects of blood pressure reduction, there were no significant differences among the three age groups in serum electrolyte levels, renal function, or carbohydrate and lipid metabolism (Table 1-B). In fact, a population-based study revealed a positive linear relation between blood pressure and longterm mortality in elderly persons (9). In an ongoing trial in hypertensive patients aged over 80 years (10), the target blood pressure is less than $150 / 80$ $\mathrm{mmHg}$. Taken together, these facts indicate that blood pressure may be safely reduced in many elderly patients to a similar level as in younger patients.

\section{Preference for Calcium Channel Blocker}

To date, only diuretics and $\beta$-blockers have been demonstrated in large-scale studies to reduce cerebrovascular and cardiovascular morbidity and mortality. Four recent guidelines $(5,11-13)$ recommended diuretics and $\beta$-blockers for the initial therapy of hypertension. However, many hypertension specialists recommend the use of angiotensin converting enzyme inhibitors and calcium channel blockers (14). In Japan, many specialists recommend calcium channel blockers and angiotensin converting enzyme inhibitors as first-line therapy for elderly patients with hypertension (8).

Our survey indicated that calcium channel blockers were the most frequently prescribed antihypertensive agent, regardless of patients' age, associated target-organ damage, or risk factors (Figs. 1, 2). The prescription rate of calcium channel blockers was far higher than those of any other classes of drug. These results are consistent with those of a previous questionnaire survey (8), in which the majority of Japanese specialists expressed preference for calcium channel blockers. In our study, more than two-fifths of patients given calcium channel blockers were treated with this class of drug alone, and the prescription rate of calcium channel blockers as monotherapy was significantly higher in patients aged 70 years or older than in the younger age groups (Fig. 1). The preference of Japanese hypertension specialists for calcium channel blockers may relate to their potent antihypertensive efficacy in a wide range of hypertensive patients. Especially in elderly patients with attenuated arterial baroreflex function $(15,16)$, calcium channel blockers are easy to use because of their low risk of reflex-induced tachycardia.

As compared with other countries, the preference of Japanese specialists for calcium channel blockers is remarkable. Although the use of calcium channel blockers and angiotensin converting enzyme inhibi- 
Table 4. Blood Pressure and Pulse Rate during Antihypertensive Therapy According to Comorbidity and Age Group

\begin{tabular}{|c|c|c|c|c|}
\hline & & $50-59$ y.o. & 60-69 y.o. & 70 y.o.- \\
\hline \multirow{3}{*}{ Control Group } & Blood pressure $(\mathrm{mmHg})$ & $149 \pm 17 / 90 \pm 8$ & $146 \pm 14 / 83 \pm 6^{*}$ & $143 \pm 19 / 82 \pm 10^{*}$ \\
\hline & Pulse rate (beats/min) & $72 \pm 9$ & $68 \pm 9$ & $72 \pm 7$ \\
\hline & $n$ & 12 & 28 & 14 \\
\hline \multicolumn{5}{|c|}{ Number of Cardiovascular Complications } \\
\hline \multirow{3}{*}{ one } & Blood pressure $(\mathrm{mmHg})$ & $135 \pm 18 / 83 \pm 9$ & $140 \pm 17 / 81 \pm 10$ & $145 \pm 15^{* *} / 77 \pm 8^{* *}$ \\
\hline & Pulse rate (beats/min) & $67 \pm 7$ & $69 \pm 9$ & $73 \pm 9$ \\
\hline & $n$ & 43 & 100 & 118 \\
\hline \multirow{3}{*}{ two } & Blood pressure $(\mathrm{mmHg})$ & $144 \pm 9 / 85 \pm 6$ & $143 \pm 13 / 74 \pm 14$ & $146 \pm 14 / 75 \pm 8$ \\
\hline & Pulse rate (beats/min) & $74 \pm 7$ & $73 \pm 11$ & $73 \pm 10$ \\
\hline & $n$ & 5 & 19 & 34 \\
\hline \multirow{3}{*}{ three or more } & Blood pressure $(\mathrm{mmHg})$ & $140 \pm 23 / 73 \pm 6$ & $144 \pm 9 / 69 \pm 7$ & $140 \pm 13 / 78 \pm 6$ \\
\hline & Pulse rate (beats/min) & $67 \pm 1$ & $70 \pm 9$ & $70 \pm 4$ \\
\hline & $n$ & 3 & 3 & 9 \\
\hline \multicolumn{5}{|c|}{ Number of Risk Factors } \\
\hline \multirow{3}{*}{ one } & Blood pressure $(\mathrm{mmHg})$ & $138 \pm 16 / 87 \pm 8$ & $140 \pm 15 / 82 \pm 9$ & $145 \pm 17 * * / 78 \pm 9 * *$ \\
\hline & Pulse rate (beats/min) & $70 \pm 9$ & $70 \pm 11$ & $72 \pm 10$ \\
\hline & $n$ & 62 & 136 & 118 \\
\hline \multirow{3}{*}{ two } & Blood pressure $(\mathrm{mmHg})$ & $141 \pm 16 / 85 \pm 10$ & $143 \pm 15 / 83 \pm 10$ & $148 \pm 18 * * / 76 \pm 9 * *$ \\
\hline & Pulse rate (beats/min) & $70 \pm 8$ & $69 \pm 9$ & $71 \pm 11$ \\
\hline & $n$ & 49 & 70 & 52 \\
\hline \multirow{3}{*}{ three or more } & Blood pressure $(\mathrm{mmHg})$ & $145 \pm 13 / 86 \pm 9$ & $138 \pm 11 / 80 \pm 9$ & $149 \pm 16 / 76 \pm 12$ \\
\hline & Pulse rate (beats/min) & $76 \pm 11$ & $68 \pm 7$ & $74 \pm 14$ \\
\hline & $n$ & 8 & 24 & 11 \\
\hline
\end{tabular}

Data are mean \pm SD. ${ }^{* *} p<0.05$ vs. 50-59 y.o., $60-69$ y.o. ${ }^{*} p<0.05 v s .50-59$ y.o. ${ }^{\dagger} p<0.05$ vs. control Group. Control group consists of patients with no complications or risk factors.

tors is increasing and that of thiazide diuretics is decreasing in Western countries $(17,18)$, thiazide diuretics and $\beta$-blockers are still the most widely prescribed antihypertensive agents. For example, in three locations in the United States (17) in 1988 and 1989 thiazide diuretics were the most commonly prescribed class of antihypertensive drug for elderly patients. The prescription rate of thiazide diuretics was $14 \%$ among patients aged 71 years or older; the next most commonly prescribed drugs were loop diuretics and calcium channel blockers. The prescription rate of calcium channel blockers in elderly patients was $11 \%$ in 1988 and 1989. Furthermore, the prescription rate of cardioselective and nonselective $\beta$-blockers combined was definitely higher than that of calcium channel blockers (17). A postal questionnaire survey performed in 1992 revealed that British physicians prefer thiazide diuretics as first-line therapy rather than calcium channel blockers (19). More than $70 \%$ of British general practitioners and about $50 \%$ of hospital physicians responded that they were likely to first prescribe a thiazide diuretic to treat hypertension. As for calcium channel blockers, less than $15 \%$ of general practitioners and about $30 \%$ of hospital physicians chose this class of drug for first-line therapy (19). Therefore, although many Western experts recommended calcium channel blockers and angiotensin converting enzyme inhibitors as first-line drugs (14), one should note that diuretics and $\beta$-blockers were the most widely prescribed agents at the time these recommendations were made.

Recently, several reports $(20,21)$ expressed a concern that short-acting calcium channel blockers may increase the risk of myocardial infarction. In addition, the use of a short-acting nifedipine preparation in patients with hypertension who were 71 years of age or older resulted in decreased survival as compared with a matched group of patients given $\beta$-blockers, whereas the use of verapamil, diltiazem, or angiotensin converting enzyme inhibitors was not associated with an increased risk of death (22). In view of the high preference of Japanese specialists for calcium channel blockers, the hypothesis that this class of drug increases the risk of myocardial infarction or long-term mortality should be investigated in future studies, even though the methodology of these reports $(20,21)$ had substantial limitations $(23,24)$. It should also be noted that the majority of calcium channel blockers prescribed in Japan are of the long-acting variety.

\section{Influence of Concurrent Diseases}

The prescription rate of each drug differed according to concurrent disease (Fig. 2). The frequent use of angiotensin converting enzyme inhibitors in patients with stroke or diabetes mellitus probably relates to the absence of adverse effects on carbohy- 
drate and lipid metabolism (25) and the presence of possible beneficial effects on the cerebral circulation $(26,27)$. Angiotensin converting enzyme inhibitors have also been reported to improve survival in patients with left ventricular dysfunction caused by myocardial infarction $(28,29)$. The frequent use of angiotensin converting enzyme inhibitors in patients with ischemic heart disease may relate to these cardioprotective effects $(28,29)$. Less frequent use of $\beta$-blockers in patients with stroke may be because this class of drugs, especially non-selective $\beta$-blockers, can cause insomnia, nightmares, or depressed mood (30). $\beta$-blockers can also adversely affect carbohydrate and lipid metabolism. Awareness of these metabolic side effects probably resulted in less frequent use of $\beta$-blockers in patients with diabetes mellitus or dyslipidemia.

Surprisingly, the prescription rate of $\beta$-blockers was slightly, but not significantly, lower in patients with ischemic heart disease than in the control group. Calcium channel blockers were prescribed in about $80 \%$ of patients, irrespective of comorbidity. This seems to relate partly to the apparent absence of metabolic side effects with calcium channel blockers. Although angina pectoris of a vasospastic nature, for which calcium channel blockers but not $\beta$-blockers are effective, has a relatively high prevalence in Japan $(31,32)$, it is unlikely that the relatively low prescription rate of $\beta$-blockers was due to a high frequency of vasospastic angina among our subjects. Because short-acting calcium channel blockers may increase the risk of myocardial infarction (20) and because $\beta$-blockers have been shown to be effective in secondary prevention of myocardial infarction (33) and probably effective in primary prevention (34), it should be emphasized that $\beta$ blockers, especially the cardioselective variety, are generally indicated in patients with ischemic heart disease associated with coronary artery stenosis.

Concurrent disease status influenced blood pressure levels during antihypertensive therapy. The results shown in the upper panel of Fig. 3 indicate that both systolic and diastolic blood pressures in patients with ischemic heart disease and diastolic blood pressure in patients with stroke were significantly lower than in the control group. In addition, when two or more cardiovascular complications were present in a single patient, diastolic pressure, but not systolic blood pressure, was again significantly lower than in the control group (Fig. 3, lower panel). These results may reflect the possibility that blood pressure was controlled more strictly in patients with advanced target-organ damage than in those with no comorbidity. However, a more plausible explanation is that these patients had lower diastolic blood pressure levels because of advanced atherosclerosis of major vessels. In either case, the blood pressure level attained was signifiicantly higher than in the normotensive patients. Among patients aged 70 years or older, blood pressure during antihypertensive therapy was similar in patients with stroke and those with no concurrent disease (Table 3). In patients with ischemic heart disease who were 70 years or older, only diastolic blood pressure was significantly lower than in the control group of the same age group (Table 3 ). Blood pressure seemed to be managed carefully in elderly patients with advanced target-organ damage to avoid extreme hypotension, because a so-called J-curve phenomenon has been observed in survivors of myocardial infarction (35) or stroke (36). Diastolic blood pressures were also significantly lower in patients with diabetes mellitus or dyslipidemia. The presence of these risk factors may also influence the blood pressure level.

In summary, the blood pressure levels of elderly patients with hypertension during antihypertensive therapy were similar to those of younger patients. Calcium channel blockers were the most frequently prescribed class of drugs, irrespective of the patients' age or condition. Furthermore, calcium channel blockers were far more frequently used as monotherapy than other classes of drugs, especially in elderly patients.

\section{Acknowledgements}

We thank Drs. Yutaka Imai of Tohoku University, Hiroshi Sekino of Chuou Clinic, Izumi Takasaki, Hiroshi Shionoiri, Satoshi Umemura, Gen Yasuda, and Osamu Tochikubo of Yokohama City University, Terunao Ashida of the Institute for Adult Diseases, Asahi Life Foundation, Atsuhiko Nomura of Aichi Medical University, Kazuko Masuo of Habara Hospital, Masatoshi Fujishima, Ken-ichiro Fujii, Tetsuhiko Nagao, Kensei Nakamura, and Hiroshi Sugimori of Kyushu University, and Shuichi Takishita, Kunitoshi Iseki, Osahiko Sunagawa, Masahiko Tozawa, Takashi Touma, and Taku Inoue of University of The Ryukyus for their cooperation.

\section{Appendix}

Affiliations of the members of The Research Group on Evaluation of the Effects of Drug Treatment on Hypertension and Other Disease Conditions in the Elderly

National Cardiovascular Center

Teruo Omae (Chief), Yuhei Kawano

Tohoku University

Keishi Abe

Yokohama City University Masao Ishii

Institute for Adult Diseases, Asahi Life Foundation Jun Fujii

Tokyo Metropolitan Institute of Gerontology Iwao Kuwajima

Aichi Medical University Toshiaki Shiomi

Osaka University Hiroshi Mikami

Kyushu University Setsuro Ibayashi

University of The Ryukyus Koshiro Fukiyama

\section{References}

1. Amery A, Birkenhäger $\mathrm{W}$, Brixko $\mathrm{P}$, et al: Mortality and morbidity results from the European Working 
Party on High Blood Pressure in the Elderly Trial. Lancet 1985; 1: 1349-1354.

2. SHEP Cooperative Research Group: Prevention of stroke by antihypertensive drug treatment in older persons with isolated systolic hypertension. Final results of the Systolic Hypertension in the Elderly Program (SHEP). JAMA 1991; 266: 3255-3264.

3. Dahlöf B, Lindholm LH, Hansson L, Schersten B, Ekbom T, Wester P-O: Morbidity and mortality in the Swedish Trial in Old Patients with Hypertension (STOP-Hypertension). Lancet 1991; 338: 1281-1285.

4. Medical Research Council Working Party: Medical Research Council trial of treatment of hypertension in older adults: principal results. $B r$ Med J 1992; 304: 405-412.

5. Joint National Committee on Detection, Evaluation, and Treatment of High Blood Pressure: The Fifth report of the Joint National Committee on Detection, Evaluation, and Treatment of High Blood Pressure (JNC V). Arch Intern Med 1993; 153: 154-183.

6. WHO Expert Committee on Diabetes Mellitus: Second Report; Technical Report Series 646, WHO, Geneva, 1985.

7. SAS Institute: SAS/STAT Guide for Personal Computers. 6th ed. Cary, North Carolina, SAS Institute, 1985.

8. Ogihara T, Morimoto S, Nakahashi T, et al: Therapeutic policy for elderly hypertensives in Japan - a questionnaire survey of specialists (in Japanese with English abstract). Jpn J Geriat 1994; 31: 396-403.

9. Glynn RJ, Field TS, Rosner B, Hebert PR, Taylor $\mathrm{JO}$, Hennekens $\mathrm{CH}$ : Evidence for a positive linear relation between blood pressure and mortality in elderly people. Lancet 1995; 345: 825-829.

10. Bulpitt CJ, Fletcher AE, Amery A, et al: The Hypertension in the Very Elderly Trial (HYVET). Rationale, methodology and comparison with previous trials. Drugs Aging 1994; 5: 171-183.

11. Ogilvie RI, Burgess E, Cusson J, Feldman RD, Leiter LA, Myers MG: Report of the Canadian Hypertension Society Consensus Conference: 3. Pharmacologic treatment of essential hypertension. Can Med Assoc J 1993; 149: 575-584.

12. Sever P, Beevers G, Bulpitt C, et al: Management guidelines in essential hypertension: report of the Second Working Party of the British Hypertension Society. Br Med J 1993; 306: 983-987.

13. Jackson R, Barham P, Bills J, et al: The management of raised blood pressure in New Zealand. $\mathrm{Br}$ Med $\mathrm{J}$ 1993; 307: 107-110.

14. Tobian L, Brunner HR, Cohn JN, et al: Modern strategies to prevent coronary sequelae and stroke in hypertensive patients differ from the JNC V Consensus Guidelines. Am J Hypertens 1994; 7: 859-872.

15. Gribbin B, Pickering TG, Sleight P, Peto R: Effect of age and high blood pressure on baroreflex sensitivity in man. Circ Res 1971; 29: 424-429, 1971.

16. Shimada K, Kitazumi T, Sadakane N, Ogura H, Ozawa T: Age related changes of baroreflex function, plasma norepinephrine, and blood pressure. Hypertension 1985; 7: 113-117.

17. Glynn RJ, Brock DB, Harris T, et al: Use of antihypertensive drugs and trends in blood pressure in the elderly. Arch Intern Med 1995; 155: 1855-1860.

18. Monane M, Glynn RJ, Gurwitz JH, Bohn RL, Levin $\mathrm{R}$, Avorn J: Trends in medication choices for hypertension in the elderly. The decline of the thiazides. Hypertension 1995; 25: 1045-1051.

19. Ford GA, Asghar MN: Management of hypertension in the elderly: attitudes of general practitioners and hospital physicians. Br J Clin Pharmac 1995; 39: 465-469.

20. Psaty BM, Heckbert SR, Koepsell TD, et al: The risk of myocardial infarction associated with antihypertensive drug therapies. JAMA 1995; 274: 620625.

21. Furberg CD, Psaty BM, Meyer JV: Nifedipine: doserelated increase in mortality in patients with coronary heart disease. Circulation 1995; 92: 1326-1331.

22. Pahor M, Guralnik JM, Corti MC, Foley DJ, Carbonin P, Havlik RJ: Long-term survival and use of antihypertensive medications in older persons. $J \mathrm{Am}$ Geriatr Soc 1995; 43: 1191-1197.

23. Opie LH, Messerli FH: Nifedipine and mortality: grave defects in the dossier. Circulation 1995; 92: 1068-1073.

24. Buring JE, Glynn RJ, Hennekens CH: Calcium channel blockers and myocardial infarction: a hypothesis formulated but not yet tested. JAMA 1995; 274: 654-655.

25. Neaton JD, Grimm RH, Jr, Prineas RJ, et al: Treatment of mild hypertension study: final results. $J A M A$ 1993; 322: 569-574.

26. Waldemar G, Schmidt JF, Andersen AR, Vorstrup $\mathrm{S}$, Ibsen $\mathrm{H}$, Paulsen OB: Angiotensin converting enzyme inhibition and cerebral blood flow autoregulation in normotensive and hypertensive man. J Hypertens 1989; 7: 229-235.

27. Torup M, Waldemar G, Paulson OB: Ceranapril and cerebral blood flow autoregulation. J Hypertens 1993; 11: 399-405.

28. Yusuf S, Pepine CJ, Garces C, et al: Effect of enalapril on myocardial infarction and unstable angina in patients with low ejection fractions. Lancet 1992; 340: $1173-1178$.

29. Pfeffer MA, Braunwald E, Moye LA, et al: Effect of captopril on mortality and morbidity in patients with left ventricular dysfunciton after myocardial infarction. Results of the survival and ventricular enlargement trail. New Engl J Med 1992; 327: 669-677.

30. Fodor JG, Chockalingam A, Drover A, Fifield F, Pauls CJ: A comparison of the side effects of atenolol and propranolol in the treatment of patients with hypertension. J Clin Pharmacol 1987; 27: 892-901.

31. Yasue H, Takizawa A, Nagao M, et al: Long-term prognosis for patients with variant angina and influential factors. Circulation 1988; 78: 1-9.

32. Shimokawa $\mathrm{H}$, Nagasawa $\mathrm{K}$, Irie $\mathrm{T}$, et al: Clinical characteristics and long-term prognosis of patients with variant angina. A comparative study between western and Japanese populations. Int $J$ Cardiol 1988; 18: 331-349.

33. Pasternak RC, Braunwald E, Sobel BE: Acute myocardial infarction, in Braunwald $E$ (ed): Heart Disease. A Textbook of Cardiovascular Medicine. Philadelphia, Saunders, 1992, pp 1200-1291.

34. Wikstrand J, Warnold I, Olsson G, Tuomilehto J, Elmfeldt D, Berglund G: Primary prevention with metoprolol in patients with hypertension. Mortality results from the MAPHY study. JAMA 1988; 259: 1976-1982.

35. D'agostino RB, Belanger AJ, Kannel WB, Cruickshank JM: Relation of low diastolic blood pressure to coronary heart disease death in presence of myocardial infarction: the Framingham study. $\mathrm{Br}$ Med $\mathrm{J}$ 1991; 303: 385-389.

36. Irie K, Yamaguchi T, Minematsu K, Omae T: The Jcurve phenomenon in stroke recurrence. Stroke 1993; 24: $1844-1849$. 